Original Article

\title{
The effect of progressive high-intensity inspiratory muscle training and fixed high-intensity inspiratory muscle training on the asymmetry of diaphragm thickness in stroke patients
}

\author{
Ju-HYeOn Jung, MS, PT ${ }^{1)}$, NAn-SOo Kim, PhD, $\left.\mathrm{PT}^{2}\right)^{*}$ \\ 1) Department of Physical Therapy, Gimhae College, Republic of Korea \\ 2) Department of Physical Therapy, College of Health Sciences, Catholic University of Pusan: 9 Bugok \\ 3-dong, Geumjung-gu, Busan 609-757, Republic of Korea
}

\begin{abstract}
Purpose] This study investigated the effects of progressive load and fixed load high-intensity inspiratory muscle training on the asymmetry of diaphragm thickness in stroke patients. [Subjects] Twenty-one stroke patients were assigned to one of three groups: progressive load high-intensity inspiratory muscle training $(\mathrm{n}=$ 8), fixed load high-intensity inspiratory muscle training $(n=6)$, and controls $(n=7)$. [Methods] The progressive load and fixed load high-intensity inspiratory muscle training participants undertook an exercise program for 20 minutes, three times weekly, for 6 weeks. After each session, diaphragm thickness was measured using ultrasonography. The diaphragm asymmetry ratio and diaphragm thickening ratio were standardized using a formula. [Results] After intervention, the diaphragm asymmetry ratio significantly differed among the three groups, and the diaphragm asymmetry ratio significantly increased in the control group. A significant increase was identified in the diaphragm thickening ratio within the progressive load and fixed load high-intensity inspiratory muscle training groups. [Conclusion] Progressive load and fixed load high-intensity inspiratory muscle training decreased the asymmetry of diaphragm thickness in stroke patients; this effect, in turn, increased the diaphragm thickening ratio in stroke patients. The two interventions examined here should be selectively applied to individuals in the clinical field.

Key words: Diaphragm thickness asymmetry, High-intensity inspiratory muscle training, Stroke
\end{abstract}

(This article was submitted Jun. 23, 2015, and was accepted Jul. 23, 2015)

\section{INTRODUCTION}

Stroke patients show impaired coughing ability owing to respiratory muscle weakness and changed chest wall kinematics. Respiratory muscle weakness appears in the acute stages of stroke ${ }^{1,2)}$. It is caused by impaired central drive to the muscles rather than reduction in intrinsic muscle strength ${ }^{1)}$. Irrespective of the mechanism, a means of improving respiratory muscle strength and central drive to the muscle may be beneficial for stroke patients ${ }^{1,3,4)}$. Furthermore, it has been reported that hemiplegia resulting from stroke damages the voluntary motor functions and coordination of the trunk muscle, causing abnormalities in posture and muscle tone ${ }^{4,5)}$, damage to motor control function necessary for coordination of the respiratory muscles ${ }^{3)}$, and increased asymmetry of the paretic and nonparetic sides of the diaphragm ${ }^{5}$.

*Corresponding author. Nan-soo Kim (E-mail: hnskim@cup. ac.kr)

(C2015 The Society of Physical Therapy Science. Published by IPEC Inc. This is an open-access article distributed under the terms of the Creative Commons Attribution Non-Commercial No Derivatives (by-ncnd) License $<$ http://creativecommons.org/licenses/by-nc-nd/3.0/>.
In patients with such neurological problems, respiratory muscle training may have a beneficial effect on respiratory muscle function. In particular, inspiratory muscle training (IMT) has been widely applied to patients suffering from different diseases to improve inspiratory muscle strength and endurance, exercise capacity, and dyspnea ${ }^{2,6-9)}$. A potential treatment aimed at enhancing muscle function and cough ability and decreasing chest infections could benefit stroke patients ${ }^{10)}$. Such a treatment could improve stroke patients' activities of daily living, quality of life, walking ability, and cardiorespiratory fitness ${ }^{1-4}$. However, interest in effective rehabilitation strategies aimed at improving stroke patients' respiratory muscle function is relatively low ${ }^{1}$.

IMT intensity and methods have been controversial in the past. In recent research, IMT training intensity has been studied for multiple diseases, and high-intensity IMT was presented as the most appropriate training method for increasing maximum inspiratory pressure (MIP), sustained MIP, lung volume, and work capacity $\left.{ }^{7}, 11,12\right)$. However, another study suggested that there was no difference between high- and low-intensity IMT, making the effectiveness of IMT controversial ${ }^{13)}$. Some preliminary clinical studies of stroke patients conducted IMT with gradual pressure load in exercise intensity according to an individual's MIP3,4). However, studies have not yet examined the effect of high- 
Table 1. Within-group and between-group comparisons of outcome measures

\begin{tabular}{|c|c|c|c|c|c|c|c|c|c|c|}
\hline & \multicolumn{2}{|c|}{ PH-IMT group $(n=8)$} & \multirow{3}{*}{$\mathrm{p}$ value $^{\mathrm{a}}$} & \multicolumn{2}{|c|}{ FH-IMT group $(n=6)$} & \multicolumn{3}{|c|}{ Control group $(n=7)$} & \multirow{2}{*}{\multicolumn{2}{|c|}{$p$ value $^{a} p$ value $e^{b}$}} \\
\hline & Pre & Post & & Pre & Post & $\mathrm{p}$ value $^{\mathrm{a}}$ & Pre & Post & & \\
\hline & \multicolumn{2}{|c|}{ Mean difference } & & \multicolumn{2}{|c|}{ Mean difference } & \multicolumn{3}{|c|}{ Mean difference } & & \\
\hline \multirow[t]{2}{*}{ Asym $D_{\text {rel }}$} & $0.05 \pm 0.05$ & $0.09 \pm 0.09$ & & $0.10 \pm 0.10$ & $0.03 \pm 0.04$ & & $0.07 \pm 0.05$ & $0.18 \pm 0.12$ & $*$ & $*$ \\
\hline & \multicolumn{2}{|c|}{$0.03 \pm 0.08^{\dagger \ddagger}$} & & \multicolumn{2}{|c|}{$-0.06 \pm 0.12^{\dagger}$} & \multicolumn{3}{|c|}{$0.10 \pm 0.09$} & & \\
\hline \multirow[t]{2}{*}{ Asym $D_{\text {con }}$} & $0.13 \pm 0.14$ & $0.10 \pm 0.11$ & & $0.16 \pm 0.12$ & $0.08 \pm 0.09$ & & $0.07 \pm 0.05$ & $0.23 \pm 0.10$ & $*$ & * \\
\hline & \multicolumn{2}{|c|}{$-0.02 \pm 0.18^{\dagger *}$} & & \multicolumn{2}{|c|}{$-0.08 \pm 0.17^{\dagger}$} & \multicolumn{3}{|c|}{$0.15 \pm 0.14$} & & \\
\hline \multirow[t]{2}{*}{ Asym TR } & $0.12 \pm 0.12$ & $0.10 \pm 0.05$ & & $0.14 \pm 0.10$ & $0.11 \pm 0.08$ & & $0.09 \pm 0.02$ & $0.13 \pm 0.09$ & & \\
\hline & \multicolumn{2}{|c|}{$-0.01 \pm 0.16$} & & \multicolumn{2}{|c|}{$-0.03 \pm 0.16$} & \multicolumn{3}{|c|}{$0.03 \pm 0.11$} & & \\
\hline \multirow[t]{2}{*}{ TR-P } & $1.65 \pm 0.26$ & $2.25 \pm 0.48$ & $*$ & $1.96 \pm 0.31$ & $2.22 \pm 0.33$ & & $1.66 \pm 0.19$ & $1.60 \pm 0.25$ & & $*$ \\
\hline & \multicolumn{2}{|c|}{$0.59 \pm 0.41^{\dagger}$} & & \multicolumn{2}{|c|}{$0.25 \pm 0.37^{\dagger \ddagger}$} & \multicolumn{3}{|c|}{$-0.06 \pm 0.24$} & & \\
\hline TR-NP & $1.65 \pm 0.32$ & $2.12 \pm 0.27$ & $*$ & $1.75 \pm 0.12$ & $2.11 \pm 0.11$ & * & $1.70 \pm 0.26$ & $1.68 \pm 0.32$ & & $*$ \\
\hline & \multicolumn{2}{|c|}{$0.46 \pm 0.26^{\dagger}$} & & \multicolumn{2}{|c|}{$0.35 \pm 0.09^{\dagger}$} & \multicolumn{3}{|c|}{$-0.01 \pm 0.30$} & & \\
\hline
\end{tabular}

${ }^{\mathrm{a}}$ Within-group comparisons. ${ }^{\mathrm{b}} \mathrm{Between}$-group comparisons.

Asym $\mathrm{D}_{\text {rel }}$ : asymmetry of diaphragm thickness at functional residual capacity; $A s y m \mathrm{D}_{\text {con }}$ : asymmetry of diaphragm thickness at total lung capacity; Asym TR: asymmetry of thickening ratio; TR-P: thickening ratio of the paretic side; TR-NP: thickening ratio of the nonparetic side

${ }^{*} \mathrm{p}<0.05 .{ }^{\dagger}{ }^{\dagger}$ Statistical significance $(\mathrm{p}<0.05)$

intensity IMT using the methods for applying pressure load to stroke patients. Therefore, this study aimed to verify the effects of progressive load high-intensity IMT (PH-IMT) and fixed load high-intensity IMT (FH-IMT) on stroke patients' diaphragm asymmetry and to identify an IMT method appropriate for stroke patients.

\section{SUBJECTS AND METHODS}

The participants were 21 stroke patients (PH-IMT group: $\mathrm{n}=8$, FH-IMT group: $\mathrm{n}=6$, control group: $\mathrm{n}=7$ ) who had a full understanding of, and voluntarily consented to participate in, this study. The stroke patients had the disease for at least 6 months. The PH-IMT group consisted of 4 males and 4 females whose average age, height, weight, and body mass index (BMI) were $56.25 \pm 6.04$ years, $157.40 \pm 7.20 \mathrm{~cm}$, $60.01 \pm 9.72 \mathrm{~kg}$, and $24.18 \pm 3.31 \mathrm{~kg} / \mathrm{m}^{2}$, respectively. The FH-IMT group consisted of 3 males and 3 females whose average age, height, weight, and BMI were $59.83 \pm$ 8.44 years, $157.83 \pm 7.70 \mathrm{~cm}, 59.76 \pm 10.70 \mathrm{~kg}$, and 23.87 $\pm 3.01 \mathrm{~kg} / \mathrm{m}^{2}$, respectively. The control group consisted of 4 males and 3 females whose average age, height, weight, and BMI were $62.85 \pm 12.82$ years, $161.58 \pm 11.95 \mathrm{~cm}$, $58.24 \pm 9.19 \mathrm{~kg}$, and $22.21 \pm 1.39 \mathrm{~kg} / \mathrm{m}^{2}$, respectively. This study was approved by the Catholic of Pusan university institutional review board (CUPIRB-2013-021). The subjects were all patients who had been diagnosed with stroke using computed tomography. The criteria for selecting subjects for this study followed the standard set by previous research ${ }^{4}$. Before applying an intervention to each group, A spirometer (CHESTGRAPH HI 101, Chest M.I. Inc., Tokyo, Japan) was used to measure pulmonary function (forced vital capacity [FVC], forced expiratory volume in 1 second $\left[\mathrm{FEV}_{1}\right], \mathrm{FEV}_{1} /$ FVC ratio, and peak expiratory flow $[\mathrm{PEF}])^{4,14)}$. Changes in diaphragm thickness were measured using ultrasonography (Logiq 7, GE Healthcare, Arizona, USA) based on a previously proposed method ${ }^{6,14,15)}$. The diaphragm thickness ratio (TR) was standardized using the following formula: TR $=$ (diaphragm thickness during MIP maneuver of functional residual capacity [FRC] / mean thickness while relaxing at FRC). The diaphragm asymmetry ratio was calculated as $\mid 1-$ (paretic diaphragm thickness/nonparetic diaphragm thickness) $\left.\right|^{5)}$.

For IMT training, a Threshold ${ }^{\circledR}$ Inspiratory Muscle Trainer (Respironics, Cedar Grove, NJ, USA) was employed using a method modified from previous studies. The PH-IMT group started to receive training with MIP $\left(\mathrm{PI}_{\max }\right)$ at $30 \%$, and exercise intensity was gradually increased by $5-10 \%$ in each session; the exercise session was considered complete when the Borg scale rating for perceived exertion score (RPE) reached 16 for each individual ${ }^{3,4,6)}$. The FH-IMT group began to receive training with $\mathrm{PI}_{\max }$ at $80 \%$ and maintained exercise intensity ${ }^{10}$. Each intervention was conducted for sessions that lasted 20 minutes, three times per week, for 6 weeks, and a total of six resting times ( 60 to $45,30,15$, 10 , and 5 seconds) were provided ${ }^{11,14)}$. The collected data were analyzed using PASW Statistics for Windows version 18.0. A paired t-test was conducted to verify changes within each group, and one-way analysis of variance was used to examine differences among the three groups. Duncan's post hoc analysis was employed. Statistical significance was set at $\mathrm{p}<0.05$.

\section{RESULTS}

The effects of the interventions over time within each group, and the results of comparisons among the groups after a 6-week intervention period, are set forth in Table 1.

\section{DISCUSSION}

Respiratory muscles, including the diaphragm, are morphologically or functionally skeletal muscles. Therefore, their responses may differ according to the type and intensity of 
training using the appropriate physiological load, as do other skeletal muscles; in addition, respiratory muscle training using an appropriate load can potentially increase diaphragm thickness ${ }^{5,11)}$. Further, in hemiplegic patients, the paretic and nonparetic sides of the diaphragm become more asymmetrical in thickness, and changes in the contraction of the diaphragm also become asymmetric; because the diaphragm is a major inspiratory muscle, this asymmetry can result in functional abnormality of the respiratory muscles ${ }^{5}$. In addition, previous studies have reported that when appropriate respiratory muscle training was not given, stroke patients' diaphragm thickness asymmetry increased, worsening their pulmonary functional disability ${ }^{4}, 5$. In the present study as well, the control group's asymmetry (Asym) of diaphragm thickness at functional residual capacity $\left(\mathrm{D}_{\text {rel }}\right)$, Asym of diaphragm thickness at total lung capacity $\left(\mathrm{D}_{\text {con }}\right)$, and Asym of TR increased by $142 \%, 214 \%$, and $33 \%$, respectively, during 6 weeks. In contrast, the Asym $\mathrm{D}_{\text {con }}$ of the PH-IMT group and the FH-IMT group decreased by $15 \%$ and $50 \%$, respectively, and the Asym TR of the PH-IMT group and FH-IMT group decreased by $8 \%$ and $21 \%$, respectively; these results were consistent with those of previous research in which the diaphragm asymmetry ratio decreased with appropriate respiratory muscle training ${ }^{5)}$. These results verify the finding that PH-IMT and FH-IMT are effective interventions for improving stroke patients' diaphragm thickness asymmetry ratio and related mobility.

This study examined whether fixed load resistance should be given during high-intensity IMT in the clinic, or whether changes in intensity should be periodically made for each session. The study results showed that both intervention methods were able to improve diaphragm thickness asymmetry ratio and diaphragm contraction. Such results were obtained because the principle of "overload", meaning that maximal training load should be applied to stimulate optimal physiologic adaptation within the skeletal muscle, was well applied ${ }^{12)}$. The diaphragm and intercostal muscles are represented by the bilateral motor cortical regions; in addition, the diaphragm is reached via the corticospinal tract and has the same structure and contraction mechanism as the muscles of the extremities ${ }^{4,16)}$. In stroke patients, damage to these mechanisms increases the muscle tone of the paretic side of the diaphragm and decreases the efficiency of contraction; further, this damage degrades the stability and mobility of the trunk ${ }^{4}$. Therefore, current research recommends the PH-IMT method based on the patient's RPE score rather than the FH-IMT method, in which high intensity should be maintained for patients whose trunk muscle tone is increased or who are at risk for high blood pressure and dizziness ${ }^{4)}$. FH-IMT is considered effective for training aimed at strengthening the diaphragm muscle by improv- ing diaphragm contractility. When high-intensity IMT is applied, individuals' clinical characteristics, fatigue level, and exercise endurance should be properly considered ${ }^{12)}$. Thus, if the two interventions examined in this study are selectively applied to individuals in the clinical field, they will be helpful for effectively improving the functioning of stroke patients.

\section{REFERENCES}

1) Pollock RD, Rafferty GF, Moxham J, et al.: Respiratory muscle strength and training in stroke and neurology: a systematic review. Int J Stroke, 2013, 8: 124-130. [Medline] [CrossRef]

2) Xiao $Y$, Luo M, Wang J, et al.: Inspiratory muscle training for the recovery of function after stroke. Cochrane Database Syst Rev, 2012, 5: CD009360. [Medline]

3) Britto RR, Rezende NR, Marinho KC, et al.: Inspiratory muscular training in chronic stroke survivors: a randomized controlled trial. Arch Phys Med Rehabil, 2011, 92: 184-190. [Medline] [CrossRef]

4) Sutbeyaz ST, Koseoglu F, Inan L, et al.: Respiratory muscle training improves cardiopulmonary function and exercise tolerance in subjects with subacute stroke: a randomized controlled trial. Clin Rehabil, 2010, 24: 240-250. [Medline] [CrossRef]

5) Kim NS, Jung JH: The effects of breathing retraining on asymmetry of diaphragm thickness in stroke patients. J Korean Soc Phys Med, 2013, 8: 263-269. [CrossRef]

6) Enright SJ, Unnithan VB, Heward C, et al.: Effect of high-intensity inspiratory muscle training on lung volumes, diaphragm thickness, and exercise capacity in subjects who are healthy. Phys Ther, 2006, 86: 345-354. [Medline]

7) Hill K, Jenkins SC, Philippe DL, et al.: High-intensity inspiratory muscle training in COPD. Eur Respir J, 2006, 27: 1119-1128. [Medline] [CrossRef]

8) Inzelberg R, Peleg N, Nisipeanu P, et al.: Inspiratory muscle training and the perception of dyspnea in Parkinson's disease. Can J Neurol Sci, 2005, 32: 213-217. [Medline] [CrossRef]

9) Fry DK, Pfalzer LA, Chokshi AR, et al.: Randomized control trial of effects of a 10 -week inspiratory muscle training program on measures of pulmonary function in persons with multiple sclerosis. J Neurol Phys Ther, 2007, 31: 162-172. [Medline] [CrossRef]

10) Jo MR, Kim NS, Jung JH: The effects of respiratory muscle training on respiratory function, respiratory muscle strength, and cough capacity in stroke patients. J Korean Soc Phys Med, 2014, 9: 399-406. [CrossRef]

11) Enright SJ, Unnithan VB: Effect of inspiratory muscle training intensities on pulmonary function and work capacity in people who are healthy: a randomized controlled trial. Phys Ther, 2011, 91: 894-905. [Medline] [CrossRef]

12) Aznar-Lain $S$, Webster $A L$, Cañete $S$, et al.: Effects of inspiratory muscle training on exercise capacity and spontaneous physical activity in elderly subjects: a randomized controlled pilot trial. Int J Sports Med, 2007, 28: 1025-1029. [Medline] [CrossRef]

13) Preusser BA, Winningham ML, Clanton TL: High- vs low-intensity inspiratory muscle interval training in patients with COPD. Chest, 1994, 106: 110-117. [Medline] [CrossRef]

14) Jung JH, Shim JM, Kwon HY, et al.: Effects of abdominal stimulation during inspiratory muscle training on respiratory function of chronic stroke patients. J Phys Ther Sci, 2014, 26: 73-76. [Medline] [CrossRef]

15) Kaneko H, Yamamura K, Mori S, et al.: Ultrasonographic evaluation of the function of respiratory muscles during breathing exercises. J Phys Ther Sci, 2009, 21: 135-139. [CrossRef]

16) Hill JM: Increase in the discharge of muscle spindles during diaphragm fatigue. Brain Res, 2001, 918: 166-170. [Medline] [CrossRef] 